Revue d'histoire de l'Amérique française

Q REVUE D.HISTOIRE DE L'AMÉRIQUE FRANÇAISE

\title{
Édition critique de Groulx
}

\section{La correspondance de Lionel Groulx}

\section{Juliette Rémillard}

Volume 36, numéro 3, décembre 1982

URI : https://id.erudit.org/iderudit/304089ar

DOI : https://doi.org/10.7202/304089ar

Aller au sommaire du numéro

Éditeur(s)

Institut d'histoire de l'Amérique française

ISSN

0035-2357 (imprimé)

1492-1383 (numérique)

Découvrir la revue

Citer ce document

Rémillard, J. (1982). Édition critique de Groulx : iX. La correspondance de Lionel Groulx. Revue d'histoire de l'Amérique française, 36(3), 474-475.

https://doi.org/10.7202/304089ar d'utilisation que vous pouvez consulter en ligne.

https://apropos.erudit.org/fr/usagers/politique-dutilisation/ 


\section{ÉDITION CRITIQUE DE LIONEL GROULX}

\section{IX - La correspondance de Lionel Groulx}

De toutes les disciplines, l'art épistolaire a toujours joué un rôle prépondérant. Que l'édition critique attache une importance primordiale à la cueillette de la correspondance de Lionel Groulx tient à la fois de la méthode adoptée dès le départ, du protocole établi et de la nécessité de la publication.

C'est une entreprise follement audacieuse. Tenter de récupérer au-delà de 3000 correspondants est sûrement de la témérité. Durant sa vie, qui s'échelonne sur une période de quatre-vingts ans, Lionel Groulx a conservé précieusement, dans un ordre alphabétique, toutes les lettres qu'il a reçues de ses parents, de ses professeurs, de ses confrères, de ses amis, de ses concitoyens. C'est donc à partir de cette volumineuse source que nous tentons de rejoindre, d'après les signatures, telle ou telle personne qui a écrit à Lionel Groulx. Ce dernier, à très peu d'exceptions près, ne conservait pas le double ou la copie de ses réponses, du moins jusque vers les années 1940. Un signe - un R - bien visible, sur la lettre, nous indique que L. G. a accordé une réponse. Comment trouver cet original?

Il faut presque le flair d'un détective, un goût inné de la recherche, du moins beaucoup d'entregent et d'astuce pour réussir pareille entreprise. Nous savons pertinemment que tel texte existe ou a existé, mais cela ne nous assure pas qu'il n'a pas été détruit, qu'il ne dort pas au fond d'une cave ou d'un tiroir... Plus le temps passe, plus la tâche s'avère difficile. Cependant, nou sommes généralement bien accueillis et les encouragements à mener à terme cette recherche ne manquent pas. Une fouille dans les diverses Archives nous donne souvent des résultats fructueux. Une fois sollicitées, certaines personnes que nous qualifions d'intelligentes, apportent avec la plus grande bienveillance les lettres qu'elles ont en leur possession.

L'impossibilité d'avoir accès à certains fonds - est-ce crainte, indifférence, pudeur, résistance aggravée du goût de monnayer ces documents - nous privera sûrement de quelques centaines de lettres. Et pourtant! Qu'on se le dise: ce sont les lettres de Lionel Groulx que nous cherchons, autographes surtout. Nous sommes assurés que ces lettres, jet spontané de l'auteur, révéleront divers aspects de Lionel Groulx, sa spontanéité, son esprit ouvert à [474] 
tous les problèmes de l'époque, sa disponibilité, son patriotisme, son amour de la jeunesse. La lecture en sera un nourrissant plaisir.

$\mathrm{Si}$, depuis les années 40 , nous avons gardé à peu près le duplicata de la correspondance, nous tentons quand même de récupérer l'original ou la photocopie. Il n'est pas rare qu'il s'y trouve des ajouts de la main même de L.G.

Peut-on parler du financement de nos recherches? N'eût été l'aide du Conseil des Arts d'Ottawa qui nous permet de nous déplacer à travers la province et ailleurs, et de nous adjoindre, à temps partiel, une personne ressource en ce domaine, des collaborateurs zélés, nous n'aurions pas obtenu les résultats acquis. Parce qu'il y a résultat.

Nous avons pu recueillir, jusqu'à aujourd'hui, 8 tiroirs remplis de deux classeurs, ce qui équivaut à 700 dossiers qui peuvent contenir, 1, 2, 3, 4, 5 lettres, mais parfois, 20, 30, 100, 150 et plus. Nous en avons tout autant «en attente», dossiers qui attendent une réponse négative ou affirmative. Nous n'avons pas terminé notre tâche. Nous avons bon espoir quand même de réussir ce tour de force.

Pour le moment, voici où nous en sommes:

Lettres à la famille .............. 352

Lettres récupérées (amis ou autres) . . . . 2425

Non retenus: introuvables .......... 1216 dossiers

En attente .................. 648 dossiers

Non inventoriés $(\mathrm{S}$ à $\mathrm{Z}) \ldots \ldots \ldots \ldots \ldots .125$ dossiers

L'équipe de l'édition critique qui met la dernière main à l'édition du Journal de jeunesse de Lionel Groulx, devra ensuite s'attaquer à cet autre défi: l'édition de cette correspondance. Ce sera, pour le patrimoine québécois, l'un de ses apports les plus précieux, et pour l'historiographie canadienne, un complément indispensable. 